\title{
Extramedullary Haematopoiesis in Axillary Lymph Nodes of Breast Carcinoma Patients Receiving Neoadjuvant Chemotherapy: A Potential Diagnostic Pitfall
}

\author{
Nahla M. Badr ${ }^{a, b}$ Claudia Roberts ${ }^{c}$ Abeer M. Shaaban ${ }^{c, d}$

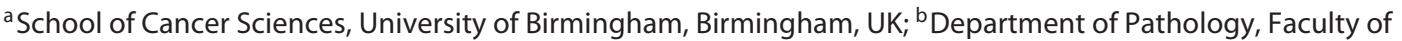 \\ Medicine, Menoufia University, Al Minufya, Egypt; ${ }^{\circ}$ Queen Elizabeth Hospital Birmingham and the University of \\ Birmingham, Birmingham, UK; ${ }^{\text {} U n i v e r s i t y ~ o f ~ T a n t a, ~ T a n t a, ~ E g y p t ~}$
}

\section{Established Facts}

- Extramedullary haematopoiesis (EMH) is mainly hosted by the lymphoid tissue and organs. However, it could be seen elsewhere.

- The process may be tri-lineage or involve one haematological lineage.

- EMH is considered a compensatory process that may indicate a haematological disorder. Other factors such as drugs may induce EMH. The precise mechanisms underlying EMH, however, remain unclear.

\section{Novel Insights}

- EMH could be seen in axillary lymph nodes of breast carcinoma patients following neoadjuvant chemotherapy especially with trastuzumab treatment.

- EMH in axillary lymph nodes should be differentiated from metastatic carcinoma and from multinucleate histiocytes. Awareness of the entity and careful attention to the morphological features including the presence/absence of atypia is crucial.

- A suggested panel of immunohistochemistry includes pan epithelial and histeocytic markers as well as markers of different blood derivatives such as CD42b, myeloperoxidase, and factor VIII.

\section{Keywords}

Extramedullary haematopoiesis · Megakaryocytes · Breast carcinoma · Axillary lymph node $\cdot$ Neoadjuvant chemotherapy $\cdot$ Herceptin

\begin{abstract}
Extramedullary haematopoiesis (EMH) in the axillary lymph node of breast cancer patients is extremely rare but when encountered can represent a diagnostic challenge. We aim to highlight this incidental finding as a diagnostic pitfall which can be mistaken for metastatic carcinoma (particularly of the metaplastic type). We report the case of a 68-year-
\end{abstract}

\section{KARGER}

(C) 2018 S. Karger AG, Basel

E-Mail karger@karger.com

www.karger.com/pat
Nahla Badr

Flat 1

16 Ribblesdale Road

Birmingham B302YP (UK)

E-Mail NMB683@student.bham.ac.uk 
old Caucasian female with a family history of cancer. Core biopsy revealed that she had grade II oestrogen receptornegative, Her2-positive invasive ductal carcinoma. She was offered neoadjuvant chemotherapy with Herceptin and subsequently underwent breast-conserving surgery. Microscopic examination of the post-treatment breast surgical specimen showed a partial pathological response with large areas of tumour regression. The sentinel lymph node showed frequent large single and multinucleate giant cells with hyperchromatic nuclei located predominantly within the subcapsular and medullary sinuses. The morphological differentials of metastatic carcinoma, sinus histiocytosis and extramedullary haematopoiesis were considered. A panel of immunohistochemistry showed these large cells to be negative for epithelial markers and CD68. They were strongly positive for CD42b (megakaryocyte marker). Smaller myeloperoxidase and factor VIII-positive cells were identified. The findings confirmed EMH. Sentinel nodes are often well scrutinised by pathologists for evidence of metastatic carcinoma as an important prognostic parameter both in the standard and neoadjuvant setting. Nodal megakaryocytes have been described in response to neoadjuvant chemotherapy particularly in association with Herceptin treatment. Pathologists' awareness of this finding in the neoadjuvant setting is crucial to avoid a mistaken diagnosis of malignancy. A relevant immunohistochemical panel together with careful attention to morphology should help establish the correct diagnosis.

(c) 2018 S. Karger AG, Basel

\section{Introduction}

Extramedullary haematopoiesis (EMH) is defined as the presence of one or more haematopoietic cell tri-lineages outside of the bone marrow [1]. It is regarded as a compensatory process associated with variable haematologic disorders that may be due to either primary or secondary aetiologies [2,3]. EMH may be induced by drugs, such as after the administration of granulocyte colonystimulating factor (G-CSF) [4]. Recently, it has been reported that this phenomenon may be associated with chemotherapy [5]. The main host of EMH is the reticuloendothelial system that includes liver, spleen, and lymph nodes [6]. EMH was also reported in other organs, including kidney, adrenals, dura mater, gastrointestinal tract, lung, pleura, and skin $[3,7,8]$. The breast was reported to host $\mathrm{EMH}$ as an incidental finding $[7,9,10]$ with a rare occurrence in axillary lymph node [1]. We report a case with EMH in a sentinel lymph node of a wide local excision specimen after treatment with neoadjuvant chemotherapy and traztuzumab. Our aim is to highlight this incidental finding as a diagnostic pitfall which can be mistaken for metastatic carcinoma.

\section{Case Presentation}

A 68-year-old, white British woman presented with a radiologically malignant mass lesion in her left breast on screening mammogram. She is a heavy smoker. She had a family history of cancer (1 of her sisters had cervical cancer at the age of 34 years and breast cancer aged 40 years; the other sister suffered from a malignant bone tumour at the age of 31 years). The breast lesion was clinically palpable. Ultrasound identified the lesion and ultrasound-guided core biopsies revealed grade II ER-negative Her2-positive invasive ductal breast cancer of no special type. Axillary nodes were normal on both clinical examination and imaging. Following multidisciplinary team discussion, the decision was made to proceed with neoadjuvant chemotherapy and traztuzumab after clip insertion to downstage the lesion and subsequently offer breast-conserving surgery. She was treated with docetaxel-FEC (2 cycles of docetaxel, 3 cycles of FEC) with concurrent traztuzumab. Imaging showed an excellent tumour response and the patient underwent ultrasound wire-guided left wide local excision with sentinel lymph node.

\section{Pathological Features}

Breast

The specimen weighed $48 \mathrm{~g}$ and measured $80 \times 65 \times 20 \mathrm{~mm}$. Microscopic examination showed a partial pathological response in the form of very few patches of grade II ductal invasive carcinoma with marked pleomorphic nuclei. There were multiple areas of tumour regression. The residual tumour was ER negative and HER2 positive.

The Sentinel Lymph Node

Throughout the node there were scattered large single and multinucleate giant cells located within the sinusoids of the cortical area as well as the medullary sinuses of the lymph nodes. The cells in places showed large nuclei with hyperchromasia and a high nucleocytoplasmic ratio, and were histologically suspicious of metastatic carcinoma (Fig. 1a, b). The presence of multiple nuclei also raised the possibility of a histiocytic proliferation. An immunohistochemistry panel for epithelial markers and macrophages, as well as haemopoietic markers, was created. These large cells were positive for CD42b (Fig. 1c), and negative for broad spectrum cytokeratin AE1/3 (Fig. 1d) and CD68 (Fig. 1e). Smaller myeloperoxidase(Fig. 1f) and factor VIII- (Fig. 1g) positive cells were identified in the background. However, both markers were negative in megakaryocytes. Careful attention to the morphological features and immunohistochemical profile confirmed these cells to be megakaryocytes. The lymph node showed no evidence of metastatic carcinoma. The diagnosis was reviewed and agreed by a haematopathologist.

\section{Follow-Up and Outcome}

Histology revealed that the medial margin of the wide local excision was positive. Therefore, a medial cavity shave was taken and showed no residual malignancy. The patient underwent adjuvant radiotherapy with adjuvant traztuzumab. She remains well after 31 months of follow-up. 
Fig. 1. Histological and immunohistochemical characteristics of nodal megakaryocytes. Low- (a) and high-power (b) magnification showing scattered large multinucleate cells from the sentinel lymph node biopsy. c CD42b-positive megakaryocytes. d Cytokeratin AE1/3-negative megakaryocytes. e CD68-negative megakaryocytes. $\mathbf{f}$ Myeloperoxidase positive for myeloid precursors and negative for megakaryocytes. g Background small cells positive for factor VIII and negative for megakaryocytes. c, d Original magnification. $\times 40$.
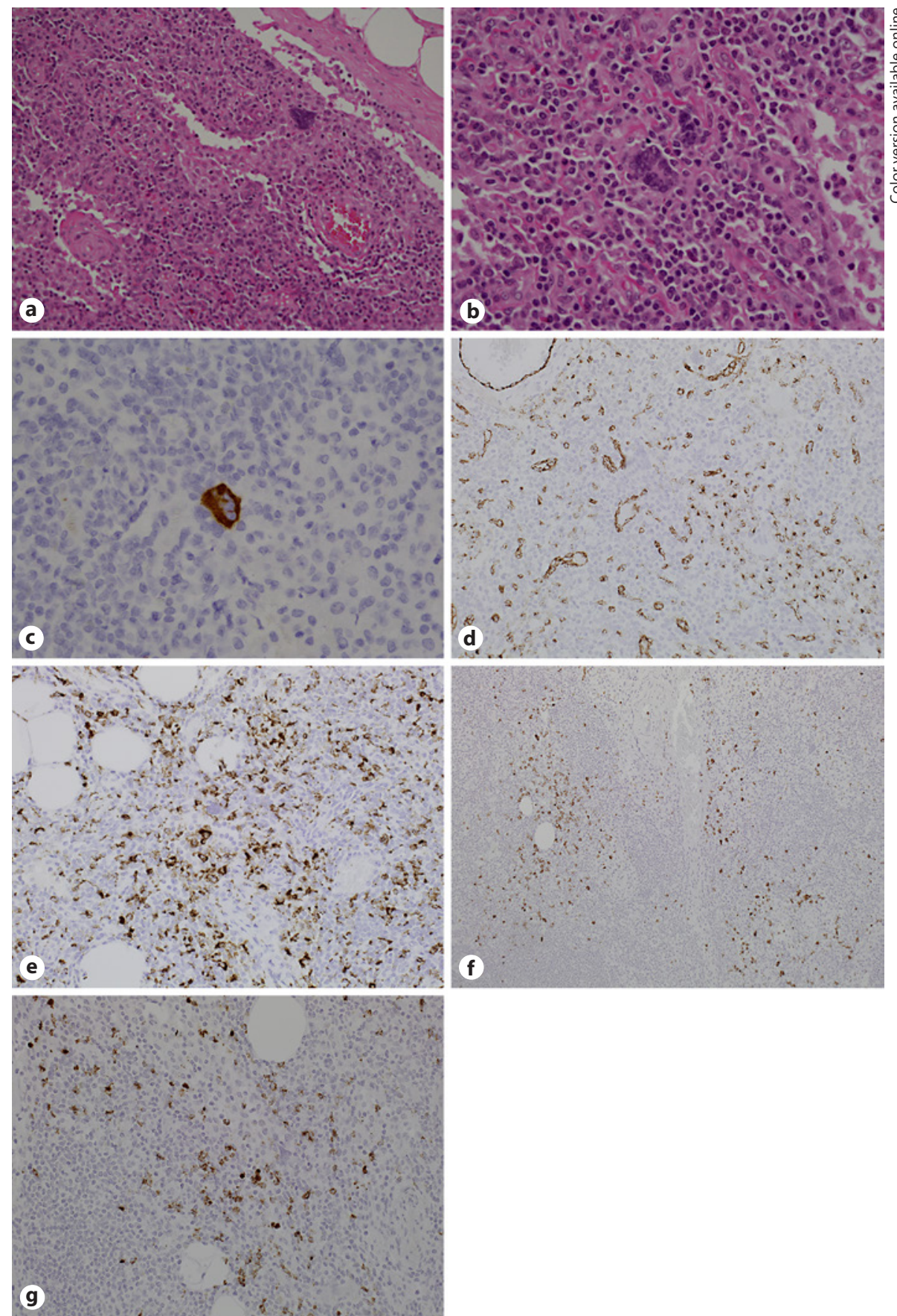

\section{Discussion}

The presence of megakaryocytes in the axillary lymph node of breast carcinoma patients is extremely rare, but when encountered can represent a diagnostic pitfall. The foci of nodal EMH could potentially be mistaken for metastatic invasive carcinoma, metaplastic carcinoma [5], or multinucleated histiocytes [11]. Histiocytes are comparatively larger and have more abundant cytoplasm with multiple vesicular nuclei, in contrast to megakaryocytes that contain multilobulated nuclei [12]. In our case, some of these cells were cytologically atypical. The presence of multinucleation, hyperchromasia, and a high nucleo-cytoplasmic ratio may lead to an erroneous diagnosis of me- 
Table 1. Summary of previous studies reporting EMH associated with breast cancer

\begin{tabular}{|c|c|c|c|c|c|c|c|}
\hline Article & Year & $\begin{array}{l}\text { Patients, } \\
n\end{array}$ & $\begin{array}{l}\text { Age, } \\
\text { years }\end{array}$ & $\begin{array}{l}\text { Screen vs. } \\
\text { symptomatic }\end{array}$ & Neoadjuvant chemotherapy & Herceptin & Node procedure \\
\hline Hoda et al. [12] & 2002 & 1 & 36 & Symptomatic & No & No & Sentinel lymphadenectomy \\
\hline $\begin{array}{l}\text { Wang and Darvishian } \\
{[17]}\end{array}$ & 2006 & 2 & 43,38 & $\begin{array}{l}1 \text { patient } \\
\text { symptomatic, } \\
\text { and } 1 \text { routine } \\
\text { screening }\end{array}$ & $\begin{array}{l}\text { Yes (doxorubicin and } \\
\text { cyclophosphamide followed } \\
\text { by paclitaxel) }\end{array}$ & No & $\begin{array}{l}\text { EMH was seen in mastectomy } \\
\text { specimens, not dissected } \\
\text { lymph nodes }\end{array}$ \\
\hline Millar et al. [13] & 2009 & 1 & 36 & Symptomatic & $\begin{array}{l}\text { Yes (docetaxel, doxorubicin, } \\
\text { cyclophosphamide followed } \\
\text { by docetaxel with G-CSF) }\end{array}$ & $\begin{array}{l}\text { Yes, } \\
\text { post- } \\
\text { operatively }\end{array}$ & Axillary node dissection \\
\hline $\begin{array}{l}\text { Prieto-Granada } \\
\text { et al. [5] }\end{array}$ & 2013 & 3 & $41-47$ & All symptomatic & Yes & No & $\begin{array}{l}1 \text { patient, } \\
\text { sentinel lymphadenectomy } \\
1 \text { patient, axillary lymph node } \\
\text { dissection } \\
1 \text { patient, core biopsy of an } \\
\text { enlarged node }\end{array}$ \\
\hline Takhar et al. [1] & 2013 & 1 & 53 & Symptomatic & $\begin{array}{l}\text { Yes (epirubicin and } \\
\text { cyclophosphamide followed } \\
\text { by docetaxel with G-CSF) }\end{array}$ & No & Axillary node dissection \\
\hline $\begin{array}{l}\text { Wilsher and Bonar } \\
{[14]}\end{array}$ & 2014 & 1 & 46 & Symptomatic & $\begin{array}{l}\text { Yes (5-fluorouracil, epirubicin } \\
\text { and cyclophosphamide } \\
\text { followed by docetaxel with } \\
\text { G-CSF) }\end{array}$ & Yes & Sentinel lymphadenectomy \\
\hline
\end{tabular}

tastasis in the context of chemotherapy. These cells should also be distinguished from multinucleated giant cells. CD68 immunohistochemistry should also be performed to exclude this possibility. Nodal megakaryocytes have been reported only for 9 individuals in 6 previous articles (summarised in Table 1). In 2002, it was first described by Hoda et al. [12] who reported the presence of megakaryocytes in axillary lymph nodes following mastectomy and axillary node sampling without prior neoadjuvant chemotherapy. All subsequent cases were reported after neoadjuvant chemotherapy with co-administration of GCSF in 3 of those cases $[1,13,14]$. Similar to our case, 2 previously reported cases had Her2 amplification [13, 14], with 1 of them receiving Herceptin on an adjuvant basis [13]. The underlying mechanism of EMH in the breast is still unknown. In 1994, Redmond et al. [4] suggested that stem cells can differentiate into haematopoietic cells in response to changes in the microenvironment. Growth factors or cytokines produced by inflammatory cells stimulated by local injury, such as biopsy or surgery, may also play a role in the pathogenesis of EMH $[3,15,16]$. Functional disruption of bone marrow causes circulating stem cells to home and proliferate in a favourable microenvironment outside the bone marrow [17]. Lymph nodes may harbour EMH as they normally sup- port the proliferation of haematopoietic progenitors, which are derived haematogenously from the bone marrow [12]. EMH was reported in other solid tumours, such as renal, lung, colonic, hepatic, endometrial, adrenal, skin, ovarian carcinomas, and melanoma [18-43]. However, the aetiology of EMH in these patients remains unclear. One hypothesis is that EMH may be induced by G-CSFs that are administrated along with chemotherapy [4] or radiotherapy. As a growth factor, G-CSF can stimulate the bone marrow to produce granulocytes by promoting stem cell production, thereby increasing the release of granulocytes into the blood. In addition, doxorubicin, which is widely used as a neoadjuvant chemotherapy for breast cancer, was linked to the pathogenesis of EMH in animal models [44]. An anaemic status results in the production of cytokines and growth factors that promote haematopoiesis. These chemical mediators may enter the blood circulation and assist in generating favourable microenvironments [17] that can elicit a natural homeostatic response to increase the production of red blood cells through a compensatory mechanism. EMH was also reported in patients receiving concurrent traztuzumab with neoadjuvant chemotherapy [13]. Poon et al. [45] suggested that trastuzumab emtansine has a cytotoxic effect that causes transient cyclic anaemia in non- 
clinical species (especially monkeys). Platelet formation experiments using human haematopoietic stem cells showed that T-DM1 can impair megakaryocyte maturation as well. Furthermore, some abnormal cytokine or paracrine growth factors may be secreted by tumour cells, which may stimulate stem cell differentiation into haematopoietic cells and evoke regional hyperplasia of circulating haematopoietic progenitors [46].

\section{Conclusion}

Axillary node sampling (either by sentinel node biopsy or axillary clearance) is considered as a standard for all breast carcinomas. Those nodes are often well scrutinised by pathologists for evidence of metastatic carcinoma, which is an important prognostic parameter both in the standard and neoadjuvant setting. It is important for pathologists reporting such cases to be aware of the phenomenon of EMH, particularly in the neoadjuvant setting, to avoid mistaking the large haematopoietically derived cells for metastatic carcinoma. We recommend that megakaryocytes should be included on the list of differential diagnoses of multinucleated giant cells in axillary lymph nodes of breast carcinoma. Epithelial immunohistochemistry as well as markers of blood derivatives (such as CD42b, myeloperoxidase, factor VIII) together with careful attention to morphology should help establish the correct diagnosis.

\section{Disclosure Statement}

The authors declare that no conflicts of interest exist.

\section{References}

1 Takhar AS, Ney A, Patel M, Sharma A. Extramedullary haematopoiesis in axillary lymph nodes following neoadjuvant chemotherapy for locally advanced breast cancer. BMJ Case Rep. 2013 May;2013:bcr2013008943.

2 Weinstein IM. Idiopathic myelofibrosis: historical review, diagnosis and management. Blood Rev. 1991 Jun;5(2):98-104.

3 Thiele J, Hoefer M, Kvasnicka HM, Bertsch HP, Zankovich R, Fischer R. Erythropoiesis in CML-immunomorphometric quantification, PCNA-reactivity, and influence on survival. Hematol Pathol. 1993;7(4):239-49.

4 Redmond J 3rd, Kantor RS, Auerbach HE, Spiritos MD, Moore JT. Extramedullary hematopoiesis during therapy with granulocyte colony-stimulating factor. Arch Pathol Lab Med. 1994 Oct;118(10):1014-5.

5 Prieto-Granada C, Setia N, Otis CN. Lymph node extramedullary hematopoiesis in breast cancer patients receiving neoadjuvant therapy: a potential diagnostic pitfall. Int J Surg Pathol. 2013 Jun;21(3):264-6.

6 Coyne JD. Extramedullary haemopoiesis. J Clin Pathol. 2005 Apr;58(4):448.

7 Cufer T, Bracko M. Myeloid metaplasia of the breast. Ann Oncol. 2001 Feb;12(2):267-70.

8 Ward HP, Vautrin R, Swasdikul D. Effect of serum from myeloproliferative disorders on erythropoietin-sensitive stem cells. J Lab Clin Med. 1971 Nov;78(5):849.

9 DiBenedetto J Jr, Dick JF, Albala M. Anemia and extramedullary hematopoiesis associated with carcinoma of the breast. Ann Clin Res. 1977 Dec;9(6):330-4.
10 Zonderland HM, Michiels JJ, ten Kate FJ. Case report: mammographic and sonographic demonstration of extramedullary haematopoiesis of the breast. Clin Radiol. 1991 Jul; 44(1):64-5.

11 Chiu A, Hoda RS, Hoda SA. Pseudomicrometastasis in sentinel lymph node-multinucleated macrophage mimicking micrometastasis. Breast J. 2001 Nov-Dec;7(6):440-1.

12 Hoda SA, Chiu A, Resetkova E, Harigopal M, Hoda RS, Osborne MP. Pathological examination of sentinel lymph node in breast cancer: potential problems and possible solutions. Microsc Res Tech. 2002 Oct;59(2):85-91.

13 Millar EK, Inder S, Lynch J. Extramedullary haematopoiesis in axillary lymph nodes following neoadjuvant chemotherapy for locally advanced breast cancer-a potential diagnostic pitfall. Histopathology. 2009 Apr;54(5): 622-3.

14 Wilsher MJ, Bonar SF. Megakaryocytes in axillary lymph nodes mimicking metastatic breast carcinoma following neoadjuvant chemotherapy and Herceptin. Pathology. 2014 Aug;46(5):453-5.

15 Wolf BC, Neiman RS. Myelofibrosis with myeloid metaplasia: pathophysiologic implications of the correlation between bone marrow changes and progression of splenomegaly. Blood. 1985 Apr;65(4):803-9.

16 Tefferi A, Yoon SY, Li CY. Immunohistochemical staining for megakaryocyte c-mpl may complement morphologic distinction between polycythemia vera and secondary erythrocytosis. Blood. 2000 Jul;96(2):771-2.
17 Wang J, Darvishian F. Extramedullary hematopoiesis in breast after neoadjuvant chemotherapy for breast carcinoma. Ann Clin Lab Sci. 2006;36(4):475-8.

18 Vassiliou V, Papamichael D, Lutz S, Eracleous E, Kountourakis P, Polyviou P, et al. Presacral Extramedullary Hematopoiesis in a Patient with Rectal Adenocarcinoma: Report of a Case and Literature Review. J Gastrointest Cancer. 2012 Sep;43(S1 Suppl 1):S131-5.

19 Hsu FI, Filippa DA, Castro-Malaspina H, Downey RJ. Extramedullary hematopoiesis mimicking metastatic lung carcinoma. Ann Thorac Surg. 1998 Oct;66(4):1411-3.

20 Pantanowitz L, Kuperman M, Goulart RA. Clinical history of HIV infection may be misleading in cytopathology. Cytojournal. 2010 Jun;7(1):7-7.

21 Meykler S, Obstfeld A, Jhala N, Vergara N, Gupta PK. Pleural mass forming extramedullary hematopoiesis masquerading as a malignant neoplasm. Diagn Cytopathol. 2015 Dec; 43(12):996-9.

22 Bowen JM, Perry AM, Quist E, Akhtari M. Extramedullary hematopoiesis in a sentinel lymph node as an early sign of chronic myelomonocytic leukemia. Case Rep Pathol. 2015; 2015:594970.

23 Ardakani NM, Kumarasinghe MP, Spagnolo DV, Stewart CJ. Extramedullary hematopoiesis associated with organizing peritoneal hemorrhage: a report of 5 cases in patients presenting with primary gynecologic disorders. Int J Gynecol Pathol. 2014;33:317-22.

24 Tokumitsu S, Tokumitsu K, Kohnoe K, Takeya M, Takeuchi T. Extramedullary hematopoiesis presenting as mediastinal tumor. Acta Pathol Jpn. 1980 Mar;30(2):315-22. 
25 Yablonski-Peretz T, Sulkes A, Polliack A, Weshler Z, Okon E, Catane R. Secondary myelofibrosis with metastatic breast cancer simulating agnogenic myeloid metaplasia: report of a case and review of the literature. Med Pediatr Oncol. 1985;13(2):92-6.

26 Crider S, Kroszer-Hamati A, Krishnan K. Isolated pancreatic extramedullary hematopoiesis. Acta Haematol. 1998;99(1):38-40.

27 Tamiolakis D, Venizelos J, Prassopoulos P, Simopoulos S, Bolioti S, Tsiapali M, et al. Intrahepatic extramedullary hematopoietic tumor mimicking metastatic carcinoma from a colonic primary. Onkologie. 2004 Feb;27(1):657.

28 Du E, Overstreet K, Zhou W, Baird G, Baird $\mathrm{S}$, Bouvet $\mathrm{M}$, et al. Fine needle aspiration of splenic extramedullary hematopoiesis presenting as a solitary mass. A case report. Acta Cytol. 2002 Nov-Dec;46(6):1138-42.

29 Yang X, Bhuiya T, Esposito M. Sclerosing extramedullary hematopoietic tumor. Ann Diagn Pathol. 2002 Jun;6(3):183-7.

30 Talmon GA. Pure erythropoiesis in clear cell renal cell carcinoma. Int J Surg Pathol. 2010 Dec;18(6):544-6.

31 Celik B, Bulut T, Sedele M, Sezer C, Karakus V. Extramedullary hematopoiesis within cystic renal cell carcinoma with oncocytic and chromophobe cell types: A case report. Oncol Lett. 2014 Mar;7(3):909-13.

32 Orphanidou-Vlachou E, Tziakouri-Shiakalli C, Georgiades CS. Extramedullary hemopoiesis. Semin Ultrasound CT MR. 2014 Jun; 35(3):255-62.
33 Tamm EP, Rabushka LS, Fishman EK, Hruban RH, Diehl AM, Klein A. Intrahepatic, extramedullary hematopoiesis mimicking hemangioma on technetium-99m red blood cell SPECT examination. Clin Imaging. 1995 Apr-Jun;19(2):88-91.

34 Arkadopoulos N, Kyriazi M, Yiallourou AI, Stafyla VK, Theodosopoulos T, Dafnios N, et al. A rare coexistence of adrenal cavernous hemangioma with extramedullar hemopoietic tissue: a case report and brief review of the literature. World J Surg Oncol. 2009 Feb;7(1): 13.

35 Dekmezian R, Sneige N, Popok S, Ordóñez NG. Fine-needle aspiration cytology of pediatric patients with primary hepatic tumors: a comparative study of two hepatoblastomas and a liver-cell carcinoma. Diagn Cytopathol. 1988;4(2):162-8.

36 Paydaş S, Sargın Ö, Gönlüşen G. PET CT imaging in extramedullary hematopoiesis and lung cancer surprise in a case with thalassemia intermedia. Turk J Haematol. 2011 Mar; 28(1):60-2.

37 Lewis DJ, Moul JW, Williams SC, Sesterhenn IA, Colon E. Perirenal liposarcoma containing extramedullary hematopoiesis associated with renal cell carcinoma. Urology. 1994 Jan; 43(1):106-9.

38 Lara JF, Rosen PP. Extramedullary hematopoiesis in a bronchial carcinoid tumor. An unusual complication of agnogenic myeloid metaplasia. Arch Pathol Lab Med. 1990 Dec; 114(12):1283-5.

39 Bosco M, Carucci P, Pacchioni D, Bruno M, Rizzetto M, Bussolati G, et al. Endoscopic ultrasound-guided fine needle aspiration diagnosis of extramedullary hematopoiesis in mediastinum. Endoscopy. 2009;41(S 02 Suppl 2):E6-7.
40 Wright PK, Thiryayi SA, Rana DN. Fine needle aspiration cytology diagnosis of extramedullary haematopoiesis presenting as a pre-sacral mass: a pitfall avoided. Cytopathology. 2012 Apr;23(2):133-4.

41 Williamson SR, Mast KJ, Cheng L, Idrees MT. Clear cell renal cell carcinoma with intratumoral and nodal extramedullary megakaryopoiesis: a potential diagnostic pitfall. Hum Pathol. 2014 Jun;45(6):1306-9.

42 Makoni SN, Laber DA. Clinical spectrum of myelophthisis in cancer patients. Am J Hematol. 2004 May;76(1):92-3.

43 Hanamornroongruang S, Neungton C, Warnnissorn M. Extramedullary hematopoiesis in the uterine cervix associated with tissue repair. Case Rep Obstet Gynecol. 2013;2013: 626130

44 Comereski CR, Peden WM, Davidson TJ, Warner GL, Hirth RS, Frantz JD. BR96-doxorubicin conjugate (BMS-182248) versus doxorubicin: a comparative toxicity assessment in rats. Toxicol Pathol. 1994 Sep-Oct; 22(5):473-88.

45 Poon KA, Flagella K, Beyer J, Tibbitts J, Kaur $\mathrm{S}$, Saad O, et al. Preclinical safety profile of trastuzumab emtansine (T-DM1): mechanism of action of its cytotoxic component retained with improved tolerability. Toxicol Appl Pharmacol. 2013 Dec;273(2):298-313.

46 Bao Y. Extramedullary hematopoiesis secondary to malignant solid tumors: a case report and literature review. Cancer Manag Res. 2018 Jun;10:1461-70. 